\title{
The 50-kDa Protein of Apple chlorotic leaf spot virus Interferes with Intracellular and Intercellular Targeting and Tubule-Inducing Activity of the 39-kDa Protein of Grapevine berry inner necrosis virus
}

\author{
M. Isogai, Y. Saitou, N. Takahashi, T. Itabashi, M. Terada, H. Satoh, and N. Yoshikawa \\ Plant Pathology Laboratory, Faculty of Agriculture, Iwate University, Ueda 3-18-8, Morioka 020-8550, Japan. \\ Submitted 8 July 2002. Accepted 19 November 2002.
}

To understand why transgenic Nicotiana occidentalis plants expressing a functional movement protein (MP) of Apple chlorotic leaf spot virus (ACLSV) show specific resistance to Grapevine berry inner necrosis virus (GINV), the MPs of ACLSV (50KP) and GINV (39KP) were fused to green, yellow, or cyan fluorescent proteins (GFP, YFP, or CFP). These fusion proteins were transiently expressed in leaf cells of both transgenic (50KP) and nontransgenic (NT) plants, and the intracellular and intercellular trafficking and tubule-inducing activity of these proteins were compared. The results indicate that in epidermal cells and protoplasts from 50KP plant leaves, the trafficking and tubuleinducing activities of GINV-39KP were specifically blocked while those of ACLSV-50KP and Apple stem grooving virus MP (36KP) were not affected. Additionally, when 39KPYFP and 50KP-CFP were coexpressed in the leaf epidermis of NT plants, the fluorescence of both proteins was confined to single cells, indicating that 50KP-CFP interferes with the cell-to-cell trafficking of 39KP-YFP and vice versa. Mutational analyses of 50KP showed that the deletion mutants that retained the activities described above still blocked cell-to-cell trafficking of $39 \mathrm{KP}$, but the dysfunctional 50KP mutants could no longer impede cell-tocell movement of 39KP. Transgenic plants expressing the functional 50KP deletion mutants showed specific resistance against GINV. In contrast, transgenic plants expressing the dysfunctional 50KP mutants did not show any resistance to the virus. From these results, we conclude that the specific resistance of $50 \mathrm{KP}$ plants to GINV is due to the ability of the 50KP to block intracellular and intercellular trafficking of GINV 39KP.

Transgenic plants expressing viral movement protein (MP) are reported to be resistant to homologous and heterologous viruses (Ares et al. 1998; Beck et al. 1994; Cooper et al. 1995; Lapidot et al. 1993; Malyshenko et al. 1993; Seppänen et al. 1997; Yoshikawa et al. 2000). The phenomenon is called MPderived resistance and, at present, may be classified into three types. In the first type of MP-derived resistance, transgenic plants expressing mutated, nonfunctional MPs show resistance to homologous viruses as well as other viruses including members in different genera (Beck et al. 1994; Cooper et al. 1995; Lapidot et al. 1993; Malyshenko et al. 1993; Seppänen et al.

Corresponding author: N. Yoshikawa;

E-mail: Yoshikawa@iwate-u.ac.jp.
1997). This type of resistance has been reported for triple gene block (TGB)-containing potexviruses and Tobacco mosaic virus (TMV). For example, transgenic plants expressing a mutated form of TGB proteins from two potexviruses, White clover mosaic virus and Potato virus X (PVX), have broadspectrum resistance against TGB-containing potex- and carlaviruses (Beck et al. 1994; Seppänen et al. 1997). Similarly, transgenic plants expressing a defective MP of TMV show resistance both to TMV and other viruses including tobra-, nepo-, alfamo-, caulimo-, and cucumoviruses (Cooper et al. 1995). In the second type of resistance, transgenic plants expressing unmodified MPs show resistance to heterologous virus in a specific manner that is not effective in the case of the homologous virus. For example, the unmodified PVX and TMV MPs can confer protection against tobamoviruses (TMV and $\mathrm{Ob}$ ) and PVX, respectively (Ares et al. 1998). The third type of resistance was reported for Trichoviruses, in which transgenic plants expressing a functional MP of Apple chlorotic leaf spot virus (ACLSV) show specific resistance to infection with Grapevine berry inner necrosis virus (GINV, another species of the genus Trichovirus) but not to infection with Apple stem grooving virus (genus Capillovirus) or Apple stem pitting virus (genus Foveavirus) (Yoshikawa et al. 2000).

Both ACLSV and GINV have flexuous filamentous particles, 740 to $760 \mathrm{~nm}$ in length and $12 \mathrm{~nm}$ in width. Each contains polyadenylated, plus-sense ssRNAs with approximately $7.5 \mathrm{~kb}$ and is composed of coat protein subunits of $22 \mathrm{kDa}$ (Yoshikawa and Takahashi 1988; van Regenmortel et al. 2000; Yoshikawa et al. 1997). Their genomes each contain three open reading frames (ORF1, ORF2, and ORF3), which encode a replication-associated protein, a MP, and a coat protein, respectively (German et al. 1990; German-Retana et al. 1997; Sato et al. 1993; Yoshikawa et al. 1997; N. Yoshikawa, unpublished data). The MP encoded by ORF2 of ACLSV (50KP) has been shown to have the following characteristics: i) 50KP is localized in plasmodesmata of infected and transgenic plant cells (Sato et al. 1995; Yoshikawa et al. 1999), ii) 50KP fused to green fluorescence protein (50KP-GFP) is targeted to plasmodesmata and accumulates in sieve elements in transgenic Nicotiana occidentalis plants (Yoshikawa et al. 1999), iii) 50KP-GFP can spread from the cells that initially produce it into neighboring cells in leaf epidermis of $N$. occidentalis (Satoh et al. 2000), iv) 50KP-GFP induces the production of tubular structures protruding from the surface of protoplasts (Satoh et al. 2000), and v) Transgenic N. occidentalis plants producing a functional $50 \mathrm{KP}$ were more susceptible to the homologous virus but showed specific resistance to the GINV (Yoshikawa et al. 2000). 
In order to understand the mechanism of MP-derived resistance against GINV in $N$. occidentalis plants expressing 50KP, we analyzed the interactions between the MPs of ACLSV and GINV in two systems. In the first, we used transgenic plant leaves expressing $50 \mathrm{KP}$, and in the second, we used nontransgenic plant leaves transiently coexpressing both proteins. The results indicate that a functional $50 \mathrm{KP}$ specifically interferes with the intracellular and intercellular trafficking and tubuleinducing activity of GINV 39KP and that this is the reason why transgenic plants expressing 50KP show specific resistance against GINV.

\section{RESULTS}

Intracellular localization and tubule-inducing activity of GINV 39KP were impeded in protoplasts from transgenic plants expressing ACLSV 50KP.

We previously reported that 50KP-GFP was distributed as small irregular spots or as a fibrous network structure on the periphery of epidermal cells and protoplasts and that it also induced the production of tubular structures protruding from the surface of protoplasts when the protein was expressed transiently in cells of $N$. occidentalis leaves (Satoh et al. 2000). In this study, we transiently expressed MPs (GINV 39KP, ACLSV 50KP, and ASGV 36KP) fused to GFP in protoplasts from transgenic $N$. occidentalis expressing 50KP (50KP plant) and compared their intracellular localization and tubule-inducing activity with those from expression in nontransgenic $N$. occidentalis (NT plant).

Both 39KP-GFP and 36KP-GFP expressed in protoplasts from NT plant leaves were present as small irregular spots and fibrous structures forming a network at the periphery of the cells (Fig. 1A, D, and G), similar to the intracellular distribution of 50KP-GFP (Satoh et al. 2000). The percentage of fluorescent protoplasts exhibiting spots or fibrous network structures at $24 \mathrm{~h}$ after transfection were 27 to $70 \%$ for $39 \mathrm{KP}-\mathrm{GFP}$ and 68 to $82 \%$ for $36 \mathrm{KP}-\mathrm{GFP}$ in three independent experi- ments. The tubular structures protruding from the surface of the protoplasts were also found in 30 to $63 \%$ of sampled protoplasts expressing 39KP-GFP and in 18 to $32 \%$ of protoplasts expressing 36KP-GFP in three independent experiments (Fig. $1 \mathrm{~B}, \mathrm{E}$, and $\mathrm{H})$. It is interesting that spots or fibrous network structures were not usually found in protoplasts producing tubular structures, similar to the results in protoplasts expressing 50KP-GFP (Satoh et al. 2000).

When 39KP-GFP was expressed in protoplasts from 50KP plant leaves, almost all fluorescence was observed as aggregates in the cytoplasm (Fig. 1F), which was never seen in 39KP-GFP-expressing NT plant leaves. Up to $90 \%$ of these protoplasts contained aggregates, and the length and number of tubules per protoplast were drastically decreased compared with the number in protoplasts from NT plant leaves. Conversely, there were no differences in intracellular distribution patterns of either 36KP-GFP or 50KP-GFP in NT and 50KP leaf protoplasts (Fig. $1 \mathrm{C}$ and I). The results indicate that $50 \mathrm{KP}$ expression in transgenic plant cells interferes with the intracellular targeting and tubule-inducing activity of 39KP-GFP but does not affect those of 36KP-GFP and 50KP-GFP.

\section{Cell-to-cell trafficking of GINV-39KP was reduced in $N$. occidentalis expressing ACLSV-50KP.}

When fluorescent $39 \mathrm{KP}$ and $36 \mathrm{KP}$ fusion proteins were transiently expressed in the leaf epidermis of NT plants using particle bombardment, fluorescence was observed as small irregular spots and as a network at the periphery of the cells in which the protein was originally produced. Both MPs also moved from the bombarded cells into the neighboring cells and localized as spots on the cell walls of the neighboring cells (Figs. 2B and 3), as previously reported for 50KP-GFP (Sato et al. 2000).

In the following experiments, 39KP-YFP, 50KP-YFP, and 36KP-YFP were transiently expressed in the leaf epidermis of $50 \mathrm{KP}$ plants. Observation by fluorescence microscopy at $24 \mathrm{~h}$ after bombardment showed that, in 50KP plants, 39KP-YFP was restricted to single cells in about $40 \%$ of cells showing fluores-
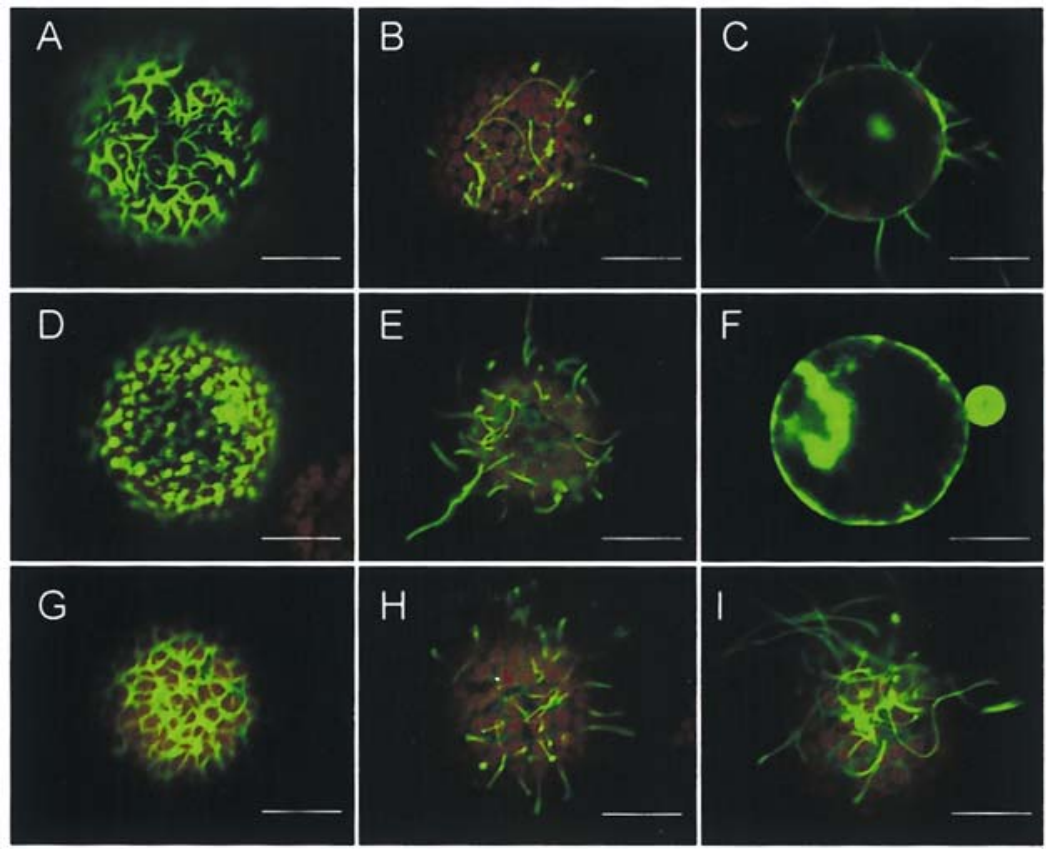

Fig. 1. Detection of fluorescence of 50KP-GFP, 39KP-GFP, and 36KP-GFP expressed transiently in protoplasts from nontransgenic Nicotiana occidentalis (NT plant) and transgenic $N$. occidentalis expressing 50KP (50KP plant) by a confocal laser scanning microscope. The 50KP-GFP, 39KP-GFP, and 36KPGFP fluorescence showing $\mathbf{A}, \mathbf{D}$, and $\mathbf{G}$, spots and fibrous structures on the periphery or $\mathbf{B}, \mathbf{E}$, and $\mathbf{H}$, tubular structures protruding from the surface of protoplasts from NT plant leaves. In protoplasts from 50KP plant leaves, F, 39KP-GFP fluorescence shows large aggregates in contrast to $\mathbf{C}$, 50KP-GFP and I, 36KP-GFP induced tubular structures as found in protoplasts from NT plant leaves. Scale bars represent $20 \mu \mathrm{m}$. 
cence and that, only in less than $5 \%$ of the cases, 39KP-YFP moved from the bombarded cells to more than seven cells (Figs. $2 \mathrm{~A}$ and 3). In contrast, in NT plant leaves, about $70 \%$ of the fluorescence spread from the bombarded cells to more than seven cells (Figs. 2B and 3). In 50KP plants, most of 39KP-YFP fluorescence that was confined within single cells formed aggregates in the cytoplasm (Fig. 2A). These aggregates were rarely observed in NT plant cells. On the other hand, both 50KP-YFP and 36KP-YFP spread from the bombarded cells into neighboring cells in leaf epidermis of 50KP plant (Figs. 2C, D, and 3). There were no differences between the cell-to-cell trafficking of 50KP and 36KP in NT- and 50KP plants (Fig. 3). These results indicate that the cell-to-cell trafficking of GINV-39KP was specifically hindered in leaf epidermis of 50KP plant.

\section{Cell-to-cell trafficking of ACLSV-50KP and GINV-39KP were blocked when both proteins were coexpressed in leaf epidermis of nontransgenic plants.}

In order to differentiate between $39 \mathrm{KP}$ and $50 \mathrm{KP}$ in tissues in which both proteins were coexpressed, we used two different fluorescent proteins (YFP and CFP). Both 39KP and 50KP fused to YFP or CFP retain their wild-type distribution in the cell periphery, localization to plasmodesmata, and ability to move from cell to cell. When 39KP-YFP was coexpressed with $50 \mathrm{KP}-\mathrm{CFP}$, the fluorescence of both $39 \mathrm{KP}-\mathrm{YFP}$ and 50KP-CFP were restricted to originally bombarded single cells in about 90\% of the fluorescent cells (Figs. 3 and 4A). Both YFP and CFP fluorescence were found in the same cells, and they formed aggregates similar to those found in epidermal cells and protoplasts from 50KP plant that transiently expresses 39KP-GFP. The spatial distribution of 39KP-YFP aggregates are consistent with those of 50KP-CFP (Fig. 4A), indicating that $39 \mathrm{KP}$ and $50 \mathrm{KP}$ colocalize in the same sites in the cytoplasm. Conversely, the cell-to-cell trafficking of 50KP-YFP and 36KP-YFP was not hindered in leaf epidermis when the proteins were coexpressed with 50KP-CFP. The cell-to-cell trafficking of 39KP-YFP was never inhibited when the protein was coexpressed with ACLSV coat protein (CP) fused to CFP, and 50KP-YFP could spread normally when coexpressed with GINV CP (Fig. 4B and C). These results indicate that 39KPYFP and 50KP-CFP specifically interfere with cell-to-cell trafficking of each other in leaf epidermis.

To determine whether their proteins or mRNAs mediated the mutual interference of cell-to-cell trafficking, p35S39KP-YFP, which expresses 39KP-YFP, was cobombarded with a mutant, p35Sstop50KP, that was not able to express 50KP (discussed below). Cell-to-cell trafficking of 39KP-YFP was blocked by cobombardment with the construct p35S50KP that expresses wild-type 50KP but not in cells cobombarded with p35Sstop50KP (Fig. 2E and F). Conversely, the cell-to-cell trafficking of 50KP-YFP was blocked in cells cobombarded with p35S39KP, which expresses 39KP, but not in cells with p35Sstop39KP, which was not able to express 39KP (Fig. 2G and $\mathrm{H}$ ). From these results, it is concluded that the proteins, not mRNAs, were involved in the mutual interference of the cellto-cell trafficking. The results also suggest that the mutual interference of their cell-to-cell trafficking between 50KP and $39 \mathrm{KP}$ is not due to gene silencing.

\section{Mutational analyses of the 50KP domain involved in the interference of cell-to-cell trafficking of $39 \mathrm{KP}$.}

To elucidate the 50KP domain involved in the interference of 39KP cell-to-cell trafficking, the p35S50KP-CFP deletion mutants (Fig. 5) were constructed by replacing the GFP gene of p35S50KP-GFP mutants (Satoh et al. 2000) with the CFP gene. When the deletion mutants were bombarded into the leaf epidermis of NT plants, the deleted proteins $(\triangle \mathrm{A}-\mathrm{CFP}, \triangle \mathrm{B}-\mathrm{CFP}$, and $\triangle \mathrm{C}-\mathrm{CFP}$ ) retained the same cell-to-cell trafficking ability as that of wild-type 50KP-CFP, and they were targeted to plasmodesmata in neighboring cells (Table 1 ). In contrast, $\triangle \mathrm{D}-\mathrm{CFP}, \triangle \mathrm{E}$ $\mathrm{CFP}, \triangle \mathrm{F}-\mathrm{CFP}$, and $\triangle \mathrm{G}-\mathrm{CFP}$ formed aggregates in the cytoplasm and lost their ability to move from cell to cell (Table 1). The results are consistent with those of p35S50KP-GFP deletion mutants described previously (Satoh et al. 2000).
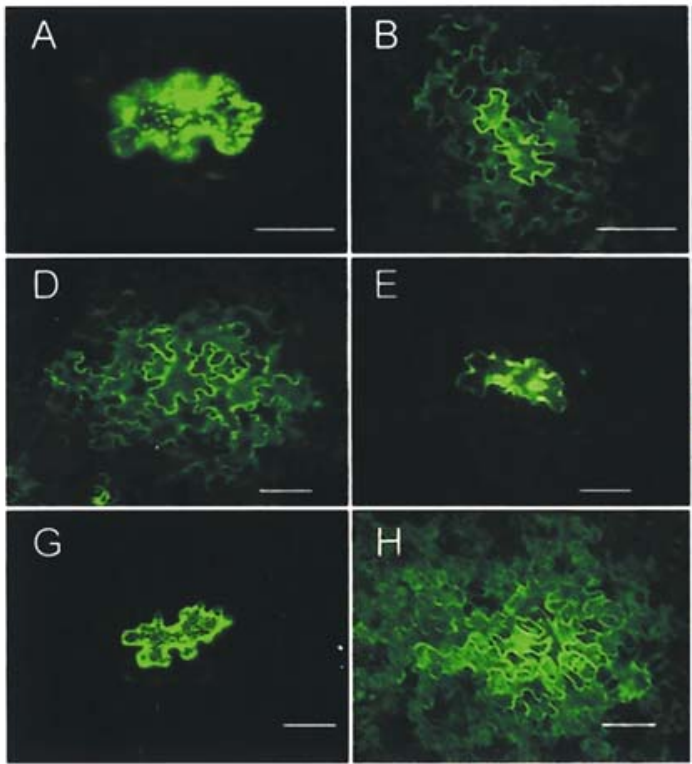
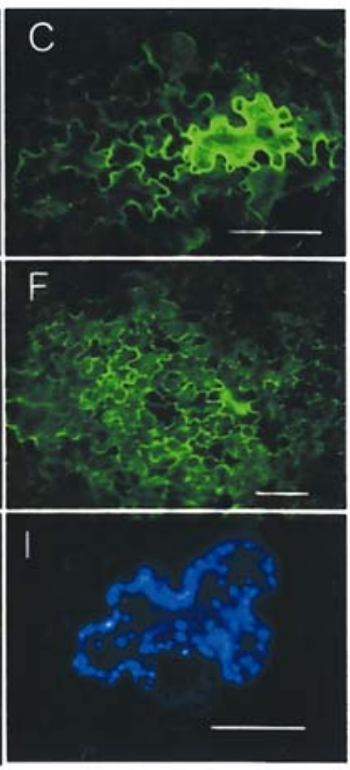

Fig. 2. Detection of fluorescence of the movement protein fused with yellow and cyan fluorescent proteins (YFP and CFP) expressed transiently in leaf epidermis of nontransgenic (NT plant) and transgenic Nicotiana occidentalis expressing 50KP (50KP plant) by a fluorescence microscope. A, 39KP-YFP confined in a single cell forms aggregates in the cytoplasm in 50KP plant. B, 39KP-YFP in the NT plant showing cell-to-cell movement. C, 50KP-YFP in the 50KP plant showing cell-to-cell movement. D, 36KP-YFP in the 50KP plant showing cell-to-cell movement. E, 39KP-YFP confined in single cell forms aggregates in the cytoplasm when coexpressed with 50KP in NT plant. F, 39KP-YFP cobombarded with p35Sstop50KP in NT plant showing cellto-cell movement. G, 50KP-YFP confined in a single cell forms aggregates in the cytoplasm when coexpressed with 39KP in NT plant. H, 50KP-YFP cobombarded with p35Sstop50KP in NT plant showing cell-to-cell movement. (I) $\triangle \mathrm{C} 2$-CFP in NT- plant confined in a single cell aggregates in the cytoplasm. Scale bars represent $50 \mu \mathrm{m}$. 
Both YFP and CFP fluorescence were confined within single cells in about $80 \%$ of the cases in which both CFP and YFP were present as aggregates in the same sites in the cytoplasm when 39KP-YFP was coexpressed with $\triangle \mathrm{A}$-CFP, $\triangle \mathrm{B}-\mathrm{CFP}$, or $\triangle \mathrm{C}-\mathrm{CFP}$ in leaf epidermis of NT plants (Fig. 4D and E; Table 1). In contrast, the fluorescence derived from 39KP-YFP spread from originally bombarded cells into neighboring cells when the protein was coexpressed with $\triangle \mathrm{D}-\mathrm{CFP}, \triangle \mathrm{E}-\mathrm{CFP}, \triangle \mathrm{F}-\mathrm{CFP}$, or $\triangle \mathrm{G}-\mathrm{CFP}$ (Fig. $4 \mathrm{~F}$ and $\mathrm{G}$, Table 1). In these cases, CFP fluorescence was present as aggregates in single cells, because they had lost their ability to move from cell to cell (Fig. $4 \mathrm{~F}$ and G).

We constructed other deletion mutants expressing $\triangle \mathrm{C} 1-\mathrm{CFP}$, $\triangle \mathrm{C} 2-\mathrm{CFP}$, and $\triangle \mathrm{C} 3-\mathrm{CFP}$ (Fig. 5). When these mutants were expressed in the leaf epidermis, $\triangle \mathrm{C} 1-\mathrm{CFP}$ spread from the cells that produced it into neighboring cells and was targeted to plasmodesmata, whereas $\triangle \mathrm{C} 2-\mathrm{CFP}$ and $\triangle \mathrm{C} 3$-CFP were restricted to single cells and formed aggregates (Fig. 2I, Table 1). In coexpression experiments, the cell-to-cell trafficking of 39KP-YFP was blocked in the presence of $\triangle \mathrm{C} 1-\mathrm{CFP}$ and $\triangle \mathrm{C} 2-\mathrm{CFP}$ (Fig. $4 \mathrm{H}$ ), but not with $\triangle \mathrm{C} 3-\mathrm{CFP}$, indicating that $\triangle \mathrm{C} 2-\mathrm{CFP}$ can interfere with the cell-to-cell trafficking of 39KP-YFP, although the protein had lost its own ability to move from cell to cell. The cell-tocell trafficking of $\triangle \mathrm{C} 2-\mathrm{CFP}$ was complemented by coexpression of 50KP-YFP but not with coexpression of 36KP-YFP (Fig. 4I and $\mathrm{J}$ ). The other mutants ( $\triangle \mathrm{D}-\mathrm{CFP}, \triangle \mathrm{E}-\mathrm{CFP}, \triangle \mathrm{F}-\mathrm{CFP}, \triangle \mathrm{G}-\mathrm{CFP}$, and $\triangle \mathrm{C} 3-\mathrm{CFP}$ ) that had lost cell-to-cell trafficking ability could not be complemented by coexpression of 50KP-YFP.

Transgenic $N$. occidentalis plants expressing a deletion mutant form of the 50KP having cell-to-cell trafficking ability were resistant to GINV.

As described above, the mutants that retain cell-to-cell trafficking ability $(\triangle \mathrm{A}-\mathrm{CFP}, \triangle \mathrm{B}-\mathrm{CFP}$, and $\triangle \mathrm{C}-\mathrm{CFP})$ can block the cell-to-cell trafficking of 39KP-YFP. In contrast, the mutants that lost their ability to move from cell to cell ( $\triangle \mathrm{D}-\mathrm{CFP}, \triangle \mathrm{E}-\mathrm{CFP}$, $\triangle F-C F P$, and $\triangle \mathrm{G}-\mathrm{CFP}$ ) do not affect the movement of $39 \mathrm{KP}$ YFP. To clarify the relationship between the 50KP's role in hindering cell-to-cell trafficking of $39 \mathrm{KP}$ and 50KP's role in the resistance against GINV seen in plants expressing 50KP, we constructed transgenic plants expressing 50KP deleted proteins $(\triangle \mathrm{A}, \Delta \mathrm{C}$, and $\triangle \mathrm{G})$, and then analyzed their responses against inoculations of ACLSV, GINV, and ASGV. Immunoblot analyses of transgenic plants expressing $\triangle \mathrm{A}, \Delta \mathrm{C}$, and $\Delta \mathrm{G}$ showed the expression of detectable levels of each deleted protein (Fig. 6). As shown in Table 2, transgenic plants expressing 50KP, $\triangle \mathrm{A}$, $\Lambda \mathrm{C}$, or 50KP-GFP did not develop symptoms after inoculation with GINV. In contrast, plants expressing $\Lambda \mathrm{G}$ or GFP showed typical symptoms of GINV. Enzyme-linked immunosorbent assays (ELISA) indicate that GINV could not accumulate in either the inoculated or upper leaves of $50 \mathrm{KP}, \triangle \mathrm{A}, \triangle \mathrm{C}$, and 50KP-GFP expressing plants (Table 2). However, GINV accumulated in both inoculated and upper leaves of plants expressing $\Delta \mathrm{G}$ or GFP. All plants expressing 50KP, the deletion mutants, 50KP-GFP, and GFP were susceptible to ACLSV and ASGV infection, and there were no differences among these plants in virus accumulation in inoculated and upper leaves. The results indicated that transgenic plants expressing the functional 50KP-deletion mutants showed specific resistance against GINV, in contrast to transgenic plants expressing dysfunctional $50 \mathrm{KP}$ mutants, which did not show any resistance to the virus.

\section{DISCUSSION}

To gain a better understanding of why $N$. occidentalis expressing 50KP showed specific resistance against GINV, we first investigated the behavior of GINV, ACLSV, and ASGV MPs tran- siently expressed in NT- and 50KP plant cells. In NT plants, both GINV-39KP and ASGV-36KP were distributed as spots or fibrous structures on the cell periphery, induced the production of tubular structures in protoplasts, and spread from initial proteins producing cells into neighboring cells in leaf epidermis. These observations indicate that they have similar functions to those previously described for ACLSV-50KP (Satoh et al. 2000). However, when expressed in cells of 50KP plants, 39KP-GFP (or YFP) formed aggregates in the cytoplasm, and its normal intracellular and intercellular trafficking was strongly blocked. In protoplasts from 50KP plants, tubule-inducing activity of 39KP was also inhibited. In contrast, the intracellular distribution, the localization to plasmodesmata, the tubule-inducing in protoplasts, and the cell-to-cell trafficking of both 50KP-GFP and 36KP-GFP were never disturbed in 50KP plant cells. Based on these results, it is reasonable to think that $50 \mathrm{KP}$ expressed in transgenic plant cells specifically blocked the functions of 39KP.

We have used two different fluorescent proteins to monitor the cell-to-cell trafficking of 39KP and 50KP simultaneously. Coexpression experiments of two MPs in which each was fused to different fluorescent proteins clearly demonstrated specific interaction between 50KP and 39KP. This technique can also be used to look for proteins (and protein domains) that inhibit the cell-to-cell trafficking of viral MPs in vivo.
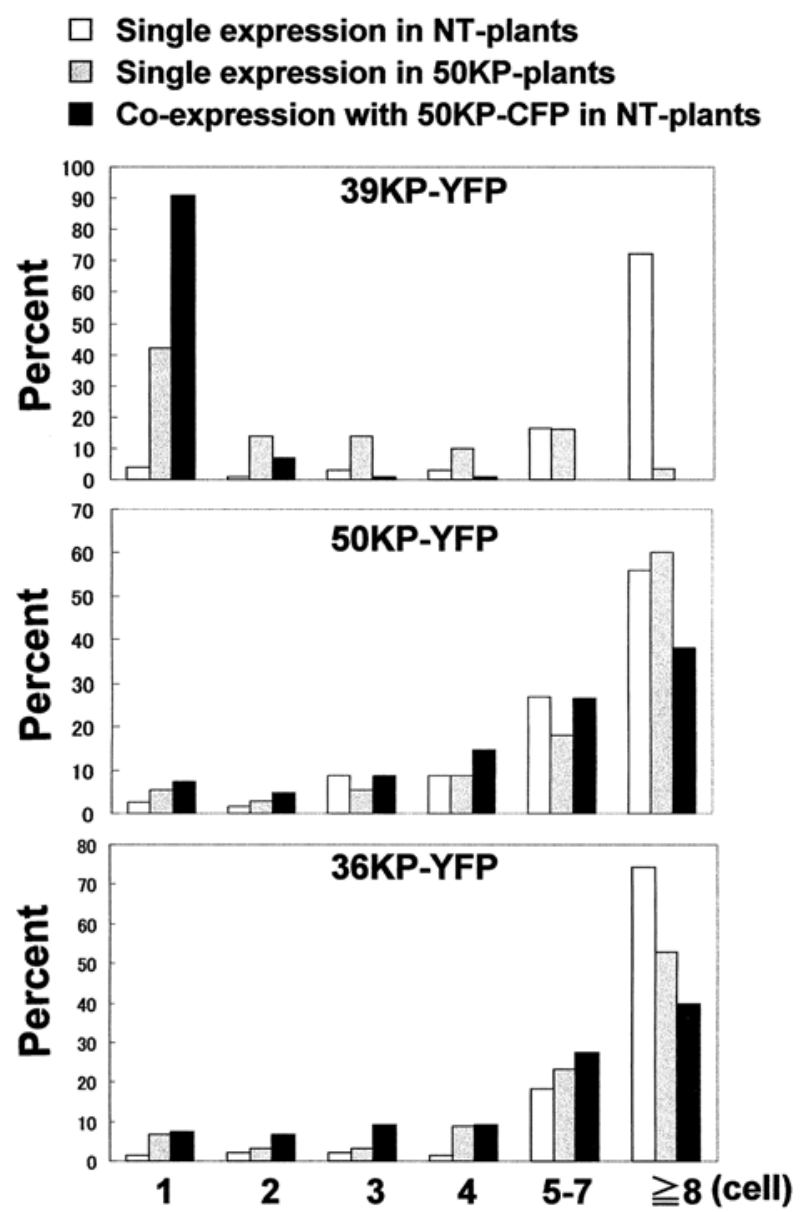

\section{Cell-to-cell spread of movement protein fused with YFP}

Fig. 3. Cell-to-cell trafficking of 39KP-YFP, 50KP-YFP, and 36KP-YFP in leaf epidermis of nontransgenic (NT plant) and transgenic Nicotiana occidentalis expressing 50KP (50KP plant). The numbers of cells showing yellow fluorescent proteins were counted $24 \mathrm{~h}$ after particle bombardment. The value (percent) is from 150 bombarded cells expressing each of the proteins in three independent leaves (50 points per leaf). 


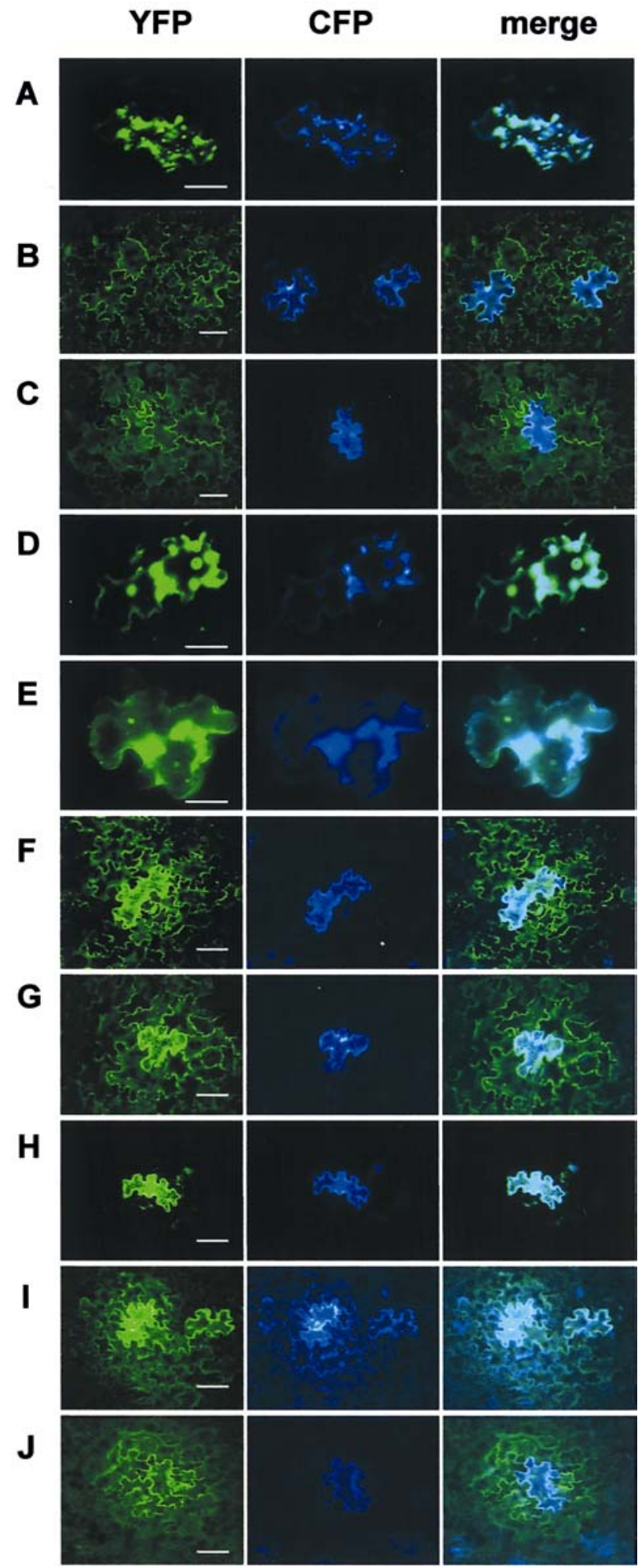

Fig. 4. Cell-to-cell trafficking of viral movement proteins fused with yellow or cyan fluorescent proteins (YFP or CFP) in coexpression experiments. YFP or CFP in leaf epidermis of nontransgenic Nicotiana occidentalis was observed $24 \mathrm{~h}$ after particle bombardment by a fluorescence microscope using filter sets XF104 for YFP and XF114 for CFP. The right column (Merge) represents an overlay of the left (YFP) and center (CFP) columns to visualize their corresponding positions. A, 39KP-YFP coexpressed with 50KP-CFP, B, 39KP-YFP coexpressed with ACLSV-CP fused with CFP, C, 50KP-YFP coexpressed with GINV-CP fused with CFP, D, 39KP-YFP coexpressed with $\triangle \mathrm{B}$-CFP, E, 39KP-YFP coexpressed with $\triangle \mathrm{C}$-CFP, F, $39 \mathrm{KP}-Y F P$ coexpressed with $\triangle \mathrm{D}-\mathrm{CFP}, \mathbf{G}, 39 \mathrm{KP}-\mathrm{YFP}$ coexpressed with $\Delta \mathrm{G}$ CFP, H, 39KP-YFP coexpressed with $\triangle \mathrm{C} 2$-CFP, I, $\triangle \mathrm{C} 2-\mathrm{CFP}$ coexpressed with 50KP-YFP, and J, $\triangle \mathrm{C} 2-\mathrm{CFP}$ coexpressed with $36 \mathrm{KP}-\mathrm{YFP}$. Scale bars represent $50 \mu \mathrm{m}$.
We previously reported that the C-terminal region (aa 287 to 457 ) of 50KP was not essential for localization to plasmodesmata, cell-to-cell trafficking, complementation of movement of $50 \mathrm{KP}$-defective virus, or tubule formation on protoplasts, and in contrast, deletions in the $\mathrm{N}$-terminal region resulted in the complete disruption of all these activities (Satoh et al. 2000). Coexpression of 39KP with a series of deleted 50KP in leaf epidermis of NT plants showed that the cell-to-cell trafficking of $39 \mathrm{KP}$ was blocked by the deleted proteins that retain the activities described above $(\triangle \mathrm{A}, \Delta \mathrm{B}, \Delta \mathrm{C}$, and $\Lambda \mathrm{C} 1)$ but not by the deleted proteins that have lost those functions $(\Lambda \mathrm{C} 3, \Delta \mathrm{D}, \Delta \mathrm{E}$, $\Delta \mathrm{F}$, and $\Delta \mathrm{G})$. Thus, the ability of 50KP to interfere with $39 \mathrm{KP}$ movement is correlated with the activities associated with localization to plasmodesmata, cell-to-cell trafficking, and tubule formation on protoplasts. Further detailed studies of the $50 \mathrm{KP}$ mutants are needed to clarify the association between these activities and the inhibition of 39KP movement. Especially, analysis of $\Lambda \mathrm{C} 2$ may provide additional evidences, because $\Lambda \mathrm{C} 2$ could inhibit the cell-to cell movement of $39 \mathrm{KP}$ in leaf epidermis even though this mutant could no longer move itself cell-to-cell.

Although we do not know exactly how 39KP and 50KP interact with each other, one probable explanation is as follows. Both 50KP and 39KP have the same intracellular targeting program, i.e., interactions with host membranes, cytoskeletal elements, and host proteins, each of which is essential for the maturation of a movement-competent protein as reported for TMV MP (Heinlein et al. 1995, 1998; Mclean et al. 1995; Reichel and Beachy 1998; Reichel et al. 1999). Therefore, the proteins encounter each other on their way to plasmodesmata (e.g., ER and cytoskeleton), and 50KP may bind to $39 \mathrm{KP}$ directly or indirectly. Consequently, malfunctioned aggregates containing both proteins may be formed in cells, and intracellular and intercellular trafficking of both proteins may be blocked. This is supported by the evidence that the spatial distribution of the 39KP-YFP aggregates was consistent with the localization of those of 50KP-CFP, indicating that the aggregates of both proteins localized to the same sites in cells. Additionally, the deleted proteins $(\Delta \mathrm{D}, \Delta \mathrm{E}, \Delta \mathrm{F}$, and $\Delta \mathrm{G})$ may not encounter $39 \mathrm{KP}$ because they have lost the ability to move in their correct way. ASGV-36KP may have a different intracellular targeting program from $50 \mathrm{KP}$ and $39 \mathrm{KP}$.

Ares and associates (1998) described a model to explain the resistance to tobamoviruses in tobacco expressing a functional p24 encoded by PVX-TGB. In this model, p24 and p30 (tobamovirus MP) contain multiple functional domains, those performing equivalent activities and those specific to each virus protein. The resistance could be explained as a competition for a limiting cellular factor that is required for both systems. If the interference between 50KP and 39KP was caused by a competition for cellular factors, it is thought that one or both of these MPs can move from bombarded cells to some extent. However, coexpression experiments showed that both $50 \mathrm{KP}$ and $39 \mathrm{KP}$ were restricted to the bombarded single cells in $90 \%$ of the cells showing fluorescence. So, it is preferable to think that the interference of cell-to-cell trafficking between $50 \mathrm{KP}$ and $39 \mathrm{KP}$ would be caused by an interaction between these proteins rather than by a competition for cellular factors. The fact that the cell-to-cell trafficking of $\Lambda \mathrm{C} 2$ was complemented by $50 \mathrm{KP}-\mathrm{YFP}$ but not $36 \mathrm{KP}$ also suggests that trichovirus MP can function through interaction among homogenous MPs. It is widely accepted for TMV that MP molecules interact with each other to form RNP complexes that may represent the cell-to-cell intermediates of viral infection (Kiselyova et al. 2001; Tzfira et al. 2000). A significant amino acid identity between $39 \mathrm{KP}$ and 50KP (36\%) suggests that they may share an interaction site and that the $50 \mathrm{KP}-39 \mathrm{KP}$ complexes may lead to disruption of their activities. 
The spread of TMV is reduced in transgenic plants expressing the dysfunctional MP mutant of TMV (Cooper et al. 1995). It is recently reported that the dysfunctional TMV-MP fused to GFP localizes to microtubules but does not target to plasmodesmata nor does it move cell to cell and that the presence of the dysfunctional TMV MP blocks an essential step in the intracellular targeting of wild-type TMV MP (Kotlizky et al. 2001). The authors suggested that the dysfunctional TMV MP interferes with host dependent processes that occur during the intracellular targeting program that makes MP movement competent (Kotlizky et al. 2001). Some aspects of this interference are similar to the results described herein, i.e., the presence $50 \mathrm{KP}$ interferes with intracellular and intercellular trafficking of 39KP and vice versa. However, the dysfunctional TMV MP does not interfere with wild-type MP targeting to plasmodesmata, although it interferes with movement function of wildtype MP. With our results, when both proteins were present in the same cell, 50KP and 39KP formed large aggregates and never localized in plasmodesmata.

As described in the introduction, several types of MP-mediated resistance have been reported so far. However, the mechanism of resistance in transgenic plants expressing MP is unclear. In this paper, we showed that the resistance of 50KP plants against GINV is probably mediated through interaction between MPs of two trichoviruses, although the possibility that $50 \mathrm{KP}$ interferes with GINV accumulation in single cells remains to be determined. We do not think that the resistance is due to gene silencing because of the following reasons: i) the $50 \mathrm{KP}$ plants are more susceptible to homologous virus (ACLSV); ii) the nucleotide sequence similarities among 50KP, 39KP, and 36KP genes are low, i.e., 39\% (39KP/50KP), $33 \%(36 \mathrm{KP} / 50 \mathrm{KP})$, and $30 \%(36 \mathrm{KP} / 39 \mathrm{KP})$, calculated by the simple homology program of DNASIS (Hitachi Software Engineering Co., Ltd., Tokyo); and iii) the proteins, not mRNAs, were involved in the mutual interference of the cell-to-cell trafficking of MPs, as described in this paper.
The resistance is so strong that we have never observed any symptoms in 50KP plants inoculated with GINV in any of our experiments. Because viral cell-to-cell movement is important in determining pathogenicity, virulence, and host range of viruses (Atabekov and Taliansky 1990; Maule 1991), we think that this strategy is a powerful tool for developing virus-resistant plants whose resistance is based on the interference of MP function. Further experiments are in progress to examine whether the virus-specific resistance described in this paper takes place between species in other genera.

\section{MATERIALS AND METHODS}

Construction of transient expression vectors.

The CFP and YFP genes were amplified from pEYFP and pECFP (Clontech, Palo Alto, CA, U.S.A.), respectively, using two primers (a forward primer, 5'-GGTACCGCGGGCCCGAGATCCACCG-3', containing a SacII site, and a reverse primer, 5'-AGAGAGAGCTCGCGGCCGCTTTACTTGTA-3', containing a $S a c$ I site). Each amplified gene was inserted into SacII and SacI sites of p35S50KP-GFP (Satoh et al. 2000) that was cut with the same enzymes, resulting in the elimination of the GFP gene. These plasmids were designated p35S50KPYFP and p35S50KP-CFP, respectively. The full-length 39KP gene of GINV (nt 5,613 to 6,662 of the GINV genome) was amplified using two primers (a forward primer, 5' GCTCTAGAATGGCTCTGATGAAGAAGACT $3{ }^{\prime}$, containing an XbaI site, and a reverse primer, 5' TCCCCGCGGTTTAGCCCATGAAGGGC 3', containing a SacII site). The ASGV-36KP gene (nt 4,788 to 5,747 of the ASGV genome) was also amplified using two primers (a forward primer, 5' GCTCTAGAATGGCTATCGTCAAC 3', containing an XbaI site, and a reverse primer, 5' TCCCCGCGGCCCGGGGGAGGAACCGTCAGA 3', containing a SacII site). The amplified 39KP and 36KP genes were restricted with $X b a I$ and SacII and were ligated to p35S50KP-YFP (or CFP) restricted with the same

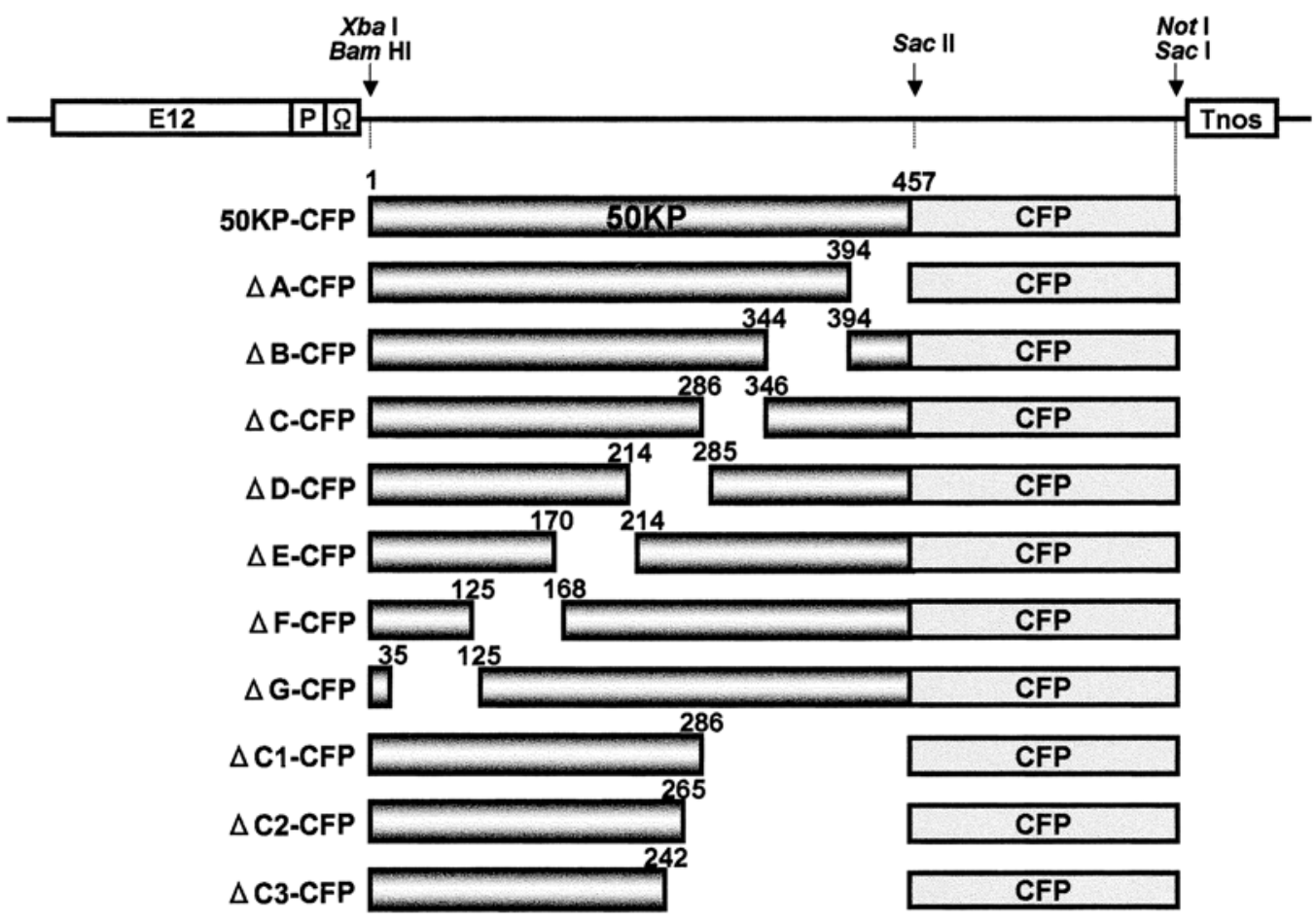

Fig. 5. Schematic representation of 50KP-CFP deletion mutants for transient expression. E12, double $5^{\prime}$ upstream sequence of CaMV $35 \mathrm{~S}$ promoter ( -419 to -90$)$; P, $5^{\prime}$ upstream sequence of $35 \mathrm{~S}$ promoter $(-90$ to -1$) ; \Omega, 5^{\prime}$-untranslated sequence of TMV; Tnos, nopaline synthease terminator. Numbers on the boxes indicate amino acid positions of 50KP. 
enzymes as above. These plasmids were designated p35S39KPYFP (or CFP) and p35S39KP-YFP (or CFP).

The 50KP-deletion mutants, $\triangle \mathrm{A}$-CFP to $\triangle \mathrm{G}$-CFP (Fig. 5), were also constructed by replacing the GFP gene of 50KP deletion mutants (Satoh et al. 2000) with CFP. For construction of three deletion mutants ( $\triangle \mathrm{C} 1-\mathrm{CFP}, \triangle \mathrm{C} 2-\mathrm{CFP}$, and $\triangle \mathrm{C} 3-\mathrm{CFP})$, deleted 50KP genes shown in Figure 5 were amplified by using a forward primer containing a BamHI site and reverse primers containing SacII site and was ligated to p35S50KP-CFP restricted with BamHI and $\mathrm{SacI}$ as above. The positions of deleted amino acids in 50KP are shown in Figure 5.

Two expression vectors, p35Sstop39KP and p35Sstop50KP, were constructed as follows. DNA fragments were amplified using mutated forward primers 5' GCTCTAGAATGGCTTGATTAAGAAGATCGCTCGT 3', containing an XbaI site (for stop39KP), and 5' CGGGATCCATGTGATAAGGGGTCACAAATTGAA 3', containing a BamHI site (for stop50KP) (italics indicate introduced stop codons) and reverse primers and, then, were inserted to $\mathrm{p} 35 \mathrm{~S}$ vector as described above. For construction of p35Sstop39KP, an in-frame stop codon was introduced to p35539KP by a base deletion at nt 5,619 of the GINV genome and also has a base change in the second in-frame AUG $(G$ to $\mathrm{T}$ at nt 5,642), leading to expression of only two amino acids from 39KP start codon. p35Sstop50KP was introduced by one base deletion (A at nt 5,730 of the ACLSV genome). This mutation resulted in generating two in-frame stop codons (nt 5,731 to 5,733 and 5,734 to 5,736) next to the 50KP start codon.

Except for expression vectors described above, p35SACCPCFP and p35GICP-CFP, which express full-length coat protein of ACLSV and GINV fused to CFP, respectively, were also

Table 1. Summary of characteristics of the 50KP-CFP deletion mutants

\begin{tabular}{lcc}
\hline Protein & Cell-to-cell trafficking & $\begin{array}{c}\text { Inhibition of } \\
\text { 39KP-YFP movement }\end{array}$ \\
\hline 50 KP-CFP & + & + \\
$\triangle \mathrm{A}-\mathrm{CFP}$ & + & + \\
$\triangle \mathrm{B}-\mathrm{CFP}$ & + & + \\
$\triangle \mathrm{C}-\mathrm{CFP}$ & + & + \\
$\triangle \mathrm{D}-\mathrm{CFP}$ & - & - \\
$\triangle \mathrm{E}-\mathrm{CFP}$ & - & - \\
$\triangle \mathrm{F}-\mathrm{CFP}$ & - & - \\
$\triangle \mathrm{G}-\mathrm{CFP}$ & - & + \\
$\triangle \mathrm{C} 1-\mathrm{CFP}$ & + & - \\
$\triangle \mathrm{C} 2-\mathrm{CFP}$ & - & + \\
$\triangle \mathrm{C} 3-\mathrm{CFP}$ & - & \\
\hline a & + and - indicate the cell-to-cell trafficking was or was not observed in \\
leaf epidermis of Nicotiana occidentalis. & \\
b and - indicate the cell-to-cell trafficking of 39KP was or was not \\
inhibited when the proteins were coexpressed in leaf epidermis of $N$. \\
occidentalis.
\end{tabular}

constructed in the same way as described above and used for experiments.

\section{Isolation and transfection of protoplasts.}

Leaf mesophyll protoplasts were isolated from nontransgenic and transgenic $N$. occidentalis leaves as described before (Satoh et al. 2000). Protoplasts were transfected with DNA constructs and incubated at $25^{\circ} \mathrm{C}$ (Satoh et al. 2000). After $24 \mathrm{~h}$, protoplasts were used for observation by fluorescence microscopy.

\section{Particle bombardment.}

Leaves 7 and 8 were detached from nontransgenic and transgenic $N$. occidentalis (12 true-leaf stage) plants and placed on a petri dish containing wet filter paper. The lower epidermis was bombarded with microparticles coated with DNA constructs using a PDS-1000/He Particle Delivery System (BioRad, Hercules, CA, U.S.A.) as described before (Satoh et al. 1999, 2000). Leaves were kept under moist conditions at $25 \mathrm{C}$ until used for observation.

\section{Fluorescence and confocal laser scanning microscopy.}

Observation of fluorescence in epidermal cells and protoplasts was conducted using a Leica DMLB fluorescence microscope, as described previously (Yoshikawa et al. 1999) using filter cubes L4 (Leica, Wetzlar, Germany) for GFP, XF114 (Omega Optical, Brattleboro, VT, U.S.A.) for CFP, and XF104 (Omega Optical) for YFP. Digital images were acquired with a 3CCD high gain color camera (Leica) and a computer program, Leica Qwin Standard V2.2 (Leica). A laser scanning microscope (a Leica DMIRB equipped with YOKOGAWA CLSM unit CSU10) was also used for observation of GFP. Digital images were acquired with a YOKOGAWA DNS10 CCD camera and processed by IPLab (Nihon Visual Science, Tokyo).

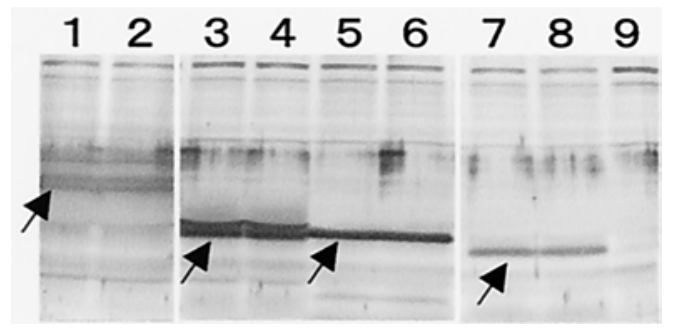

Fig. 6. Immunoblot analyses of transgenic Nicotiana occidentalis expressing 50KP deletion mutants $(\triangle \mathrm{A}, \Delta \mathrm{C}$, and $\Delta \mathrm{G})$ of Apple chlorotic leaf spot virus. Lanes 1 and 2 , transgenic plant expressing $50 \mathrm{KP}(50 \mathrm{KP}$ plant); lanes 3 and 4, $\triangle \mathrm{A}$-plant; lanes 5 and $6, \Delta \mathrm{C}$-plant; lanes 7 and $8, \Delta \mathrm{G}$; lane 9 , nontransgenic plant. Arrows indicate the positions of the expressed proteins.

Table 2. Responses of transgenic Nicotiana occidentalis plants ${ }^{\mathrm{a}}$

\begin{tabular}{|c|c|c|c|c|}
\hline \multirow[b]{2}{*}{ Plant } & \multirow[b]{2}{*}{ Line } & \multicolumn{3}{|c|}{ No. of plants with symptoms per plants } \\
\hline & & GINV & ACLSV & ASGV \\
\hline Nontransgenic & & $12 / 12(+/+)^{\mathrm{b}}$ & $8 / 8(+/+)$ & $0 / 4(+/+)^{\mathrm{c}}$ \\
\hline $50 \mathrm{KP}$ & (d-5) & $0 / 8(-/-)$ & $8 / 8(+/+)$ & $0 / 4(+/+)$ \\
\hline$\triangle \mathrm{A}$ & $(\mathrm{A}-3)$ & $0 / 8(-/-)$ & $8 / 8(+/+)$ & $0 / 4(+/+)$ \\
\hline \multirow[t]{2}{*}{$\Delta \mathrm{C}$} & $(\mathrm{C}-3)$ & $0 / 8(-/-)$ & $4 / 4(+/+)$ & $0 / 8(+/+)$ \\
\hline & (C-4) & $0 / 8(-/-)$ & $4 / 4(+/+)$ & nt \\
\hline \multirow[t]{2}{*}{$\Delta \mathrm{G}$} & (G-23) & $8 / 8(+/+)$ & $8 / 8(+/+)$ & nt \\
\hline & (G-24) & $7 / 8(+/+)$ & $8 / 8(+/+)$ & $0 / 4(+/+)$ \\
\hline 50KP-GFP & (O50G-5) & $0 / 4(-/-)$ & $4 / 4(+/+)$ & $0 / 4(+/+)$ \\
\hline GFP & $(\mathrm{OG}-5)$ & $4 / 4(+/+)$ & $4 / 4(+/+)$ & $0 / 4(+/+)$ \\
\hline
\end{tabular}

${ }^{a}$ Plalnts expressing 50KP deletion mutants $(\triangle \mathrm{A}, \triangle \mathrm{C}$ and $\triangle \mathrm{G})$ of Apple chlorotic leaf spot virus (ACLSV) against inoculations by ACLSV, Grapevine berry inner necrosis virus (GINV), or Apple stem grooving virus (ASGV).

$\mathrm{b}+$ and - in parentheses indicate that viruses were or were not detected in inoculated leaves or upper uninoculated leaves by ELISA assay, respectively. nt $=$ not tested.

c ASGV infected N. occidentalis plants symptomlessly. 


\section{Construction of plasmids expressing} 50KP deleted proteins and plant transformation.

Plasmids pBE2113- $\triangle \mathrm{A}$, pBE2113- $\Lambda \mathrm{C}$, and pBE2113 $\Delta \mathrm{G}$, which express $50 \mathrm{KP}$ deleted proteins $\triangle \mathrm{A}, \Delta \mathrm{C}$, and $\Lambda \mathrm{G}$, respectively, were constructed as described previously (Satoh et al. 2000; Yoshikawa et al. 1999, 2000). The plasmids were transformed into Escherichia coli and transferred to Agrobacterium tumefaciens LBA 4404 by electroporation (Yoshikawa et al. 2000).

Leaves of Nicotiana occidentalis '37B' were inoculated with the transformed A. tumefaciens, and the transformants were induced to regenerate shoots and roots, as described before (Yoshikawa et al. 2000). R1 seedlings were analyzed by immunoblot analysis to confirm the expression of deleted proteins and then were used for virus inoculation.

\section{Mechanical inoculation of viruses.}

Viruses used in this study were ACLSV (P-205), GINV, and ASGV (P-209). Inocula were prepared as described before (Yoshikawa et al. 2000). In addition to transgenic plants expressing $\triangle \mathrm{A}, \triangle \mathrm{C}$, and $\Lambda \mathrm{G}$ constructed in this study, transgenic plants expressing 50KP, 50KP-GFP, and GFP (Yoshikawa et al. 1999, 2000) were used for inoculation tests.

R1 seedlings of transgenic $N$. occidentalis plants were grown to the six- to seven-leaf stage in pots. Three leaves per plant were mechanically inoculated with each virus and were grown in a growth chamber for symptom observation as described before (Yoshikawa et al. 2000).

Inoculated and uninoculated upper leaves were collected at two and three weeks after inoculation, respectively, and were assayed by indirect ELISA (Yoshikawa et al. 2000).

\section{ACKNOWLEDGMENTS}

We thank A. O. Jackson and J. Bragg, University of California, Berkeley, for their critical reading of the manuscript and helpful comments. This work was supported by research grants (no. 12660039 and 13039004) from the Japanese Ministry of Education, Culture, Sports, Science, and Technology.

\section{LITERATURE CITED}

Ares, X., Calamante, G., Cabral, S., Jodge, J., Hemenway, P., Beachy, R. N., and Mentaberry, A. 1998. Transgenic plants expressing potato virus $\mathrm{X}$ ORF2 protein (p24) are resistant to tobacco mosaic virus and $\mathrm{Ob}$ tobamoviruses. J. Virol. 72:731-738.

Atabekov, J. G., and Taliansky, M. E. 1990. Expression of a plant viruscoded transport function by different viral genomes. Adv. Virus Res. 216:197-201.

Beck, D. L., Van Dolleweerd, C. J., Lough, T. J., Balmori, E., Voot, D. M., Andersen, M. T., O'Brien, I. E. W., and Forster, R. L. S. 1994. Disruption of virus movement confers broad-spectrum resistance against systemic infection by plant viruses with a triple gene block. Proc. Natl. Acad. Sci. U.S.A. 91:10310-10314.

Cooper, B., Lapidot, M., Heick, J. A., Dodds, J. A., and Beachy, R. N. 1995. A defective movement protein of TMV in transgenic plants confers resistance to multiple viruses whereas the functional analog increases susceptibility. Virology 206:307-313.

German, S., Candresse, T., Lanneau, M., Huet, J. C., Pernollet, J. C., and Dunez, J. 1990. Nucleotide sequence and genome organization of apple chlorotic leaf spot closterovirus. Virology 179:104-112.

German-Retana, S., Bergey, B., Delbos, R. P., Candresse, T., and Dunez, J. 1997. Complete nucleotide sequence of the genome of a severe cherry isolate of apple chlorotic leaf spot tricovirus (ACLSV). Arch. Virol. 142:833-841.

Heinlein, M., Epel, B. L., Padgett, H. S., and Beachy, R. N. 1995. Interaction of tobamovirus movement proteins with the plant cytoskeleton.
Science 270:1983-1985

Heinlein, M., Padgett, H. S., Gens, J. S., Pickard, B. G., Casper, S. J., Epel, B. L., and Beachy, R. N. 1998. Changing patterns of localization of the tobacco mosaic virus movement protein and replicase to the endoplasmic reticulum and microtubules during infection. Plant Cell 10:1107-1120.

Kiselyova, O. I., Yaminsky, I. V., Karger, E. M., Frolova, O. Yu., Dorokhov, Y. L., and Atabekov, J. G. 2001. Visualization by atomic force microscopy of tobacco mosaic virus movement protein-RNA complexes formed in vitro. J. Gen. Virol. 82:1503-1508.

Kotlizky, G., Katz, A., van der Laak, J., Boyko, V., Lapidot, M., Beachy, R. N., Heinlein, M., and Epel, B. E. 2001. A dysfunctional movement protein of tobacco mosaic virus interferes with targeting of wild-type movement protein to microtubules. Mol. Plant-Microbe Interact. 14:895-904.

Lapidot, M., Gafny, R., Ding, B., Wolf, S., Lucas, W. J., and Beachy, R. N. 1993. A dysfunctional movement protein of tobacco mosaic virus that partially modifies the plasmodesmata and limits virus spread in transgenic plants. Plant J. 4:959-970.

Malyshenko, S. I., Kondakova, O. A., Nazarova, Ju. V., Kaplan, I. B., Taliansky, M. E., and Atabekov, J. G. 1993. Reduction of tobacco mosaic virus accumulation in transgenic plants producing non-functional viral transport proteins. J. Gen. Virol. 74:1149-1156.

Maule, A. 1991. Virus movement in infected plants. Crit. Rev. Plant Sci. 9:457-473.

McLean, B. G., Zupan, J., and Zambryski, P. 1995. Tobacco mosaic virus movement protein associates with the cytoskeleton in tobacco cells. Plant Cell 7:2101-2114.

Reichel, C., and Beachy, R. N. 1998. Tobacco mosaic virus infection induces severe morphological changes of the endoplasmic reticulum. Proc. Natl. Acad. Sci. U.S.A 95:11169-11174.

Reichel, C., Mas, P., and Beachy, R. N. 1999. The role of the ER and cytoskeleton in plant viral trafficking. Trends Plant Sci. 4:458-462.

Sato, K., Yoshikawa, N., and Takahashi, T. 1993. Complete nucleotide sequence of the genome of an apple isolate of apple chlorotic leaf spot virus. J. Gen. Virol. 74:1927-1931.

Sato, K., Yoshikawa, N., Takahashi, T., and Taira, H. 1995. Expression, subcellular location and modification of the $50 \mathrm{kDa}$ protein encoded by ORF2 of the apple chlorotic leaf spot trichovirus genome. J. Gen. Virol. 76:1503-1507.

Satoh, H., Yoshikawa, N., and Takahashi, T. 1999. Construction and biolistic inoculation of an infectious cDNA clone of apple chlorotic leaf spot trichovirus. Ann. Phytopathol. Soc. Jpn. 65:301-304.

Satoh, H., Matsuda, H., Kawamura, T., Isogai, M., Yoshikawa, N., and Takahashi, T. 2000. Intracellular distribution, cell-to-cell trafficking and tubule-inducing activity of the $50 \mathrm{kDa}$ movement protein of Apple chlorotic leaf spot virus fused to green fluorescent protein. J. Gen. Virol. 81:2085-2093.

Seppänen, P. Puska, R., Honkanen, J., Tyulkina, L. G. Fedorkin, O., Morozov, S. Yu., and T Atabekov, J. G. 1997. Movement protein-derived resistance to triple gene block-containing plant viruses. J. Gen. Virol. 78:1241-1246.

Tzfira, T., Rhee, Y., Chen, M.-H., Kunik, T., and Citovsky, V. 2000. Nucleic acid transport in plant-microbe interactions: The molecules that walk through the walls. Ann Rev. of Microbiol. 54:187-219.

van Regenmortel, M. H. V., Fauquet, C. M., Bishop, D. H. L., Carstens, E. B., Estes, M. K., Lemon, S. M., Maniloff, J., Mayo, M. A., McGeoch, D. J., Pringle, C. R., Wickner, R. B. 2000. Virus taxonomy. Pages 956-960 in: Seventh Report of the International Committee on Taxonomy of Viruses. Academic Press, San Diego, CA, U.S.A.

Yoshikawa, N., and Takahashi, T. 1988. Properties of RNAs and proteins of apple stem grooving and apple chlorotic leaf spot viruses. J. Gen. Virol. 69:241-245.

Yoshikawa, N., Iida, H., Goto, S., Magome, H., Takahashi, T., and Terai, Y. 1997. Grapevine berry inner necrosis, a new trichovirus: Comparative studies with several known trichoviruses. Arch. Virol. 142:1351-1363.

Yoshikawa, N., Oogake, S., Terada, M., Miyabayashi, S., Ikeda, Y., Takahashi, T., and Ogawa, K. 1999. Apple chlorotic leaf spot virus 50$\mathrm{kDa}$ protein is targeted to plasmodesmata and accumulated in sieve elements in transgenic plant leaves. Arch. Virol. 144:2475-2483.

Yoshikawa, N., Goto, S., Umezawa, M., Satoh, N., Satoh, H., Takahashi, T., Ito, T., and Yoshida, K. 2000. Transgenic Nicotiana occidentalis plants expressing the 50-KDa protein of Apple chlorotic leaf spot virus display increased susceptibility to homologous virus, but strong resistance to Grapevine berry inner necrosis virus. Phytopathology 90:311-316. 